DANIELLA TRUJILLO OSPINA*

Pontificia Universidad Javeriana (Cali, Colombia)

DANIEL ROJAS-LOZANO**

FLACSO (Ciudad de México, México)

NATALIA LÓPEZ CERQUERA $* * *$

FLACSO (Quito, Ecuador)

\title{
Desbordamiento del extractivismo minero en Colombia: el caso de Suárez, Cauca
}

\author{
Outpouring of mining extractivism in Colombia: \\ the case of Suárez, Cauca
}

Excesso de extrativismo mineiro na Colômbia: o caso do município de Suárez, no departamento del Cauca

\footnotetext{
* Antropóloga de la Universidad ICESI. Investigadora de la línea de Ordenamiento Territorial y Desarrollo Rural Aplicado del Instituto de Estudios Interculturales de la Pontificia Universidad Javeriana de Cali, Colombia. Correo electrónico: datrujillo4@gmail.com ORCID: https://orcid.org/oooo-0oo2-0664-5198

** Maestro en Ciencias Sociales, Flacso - México. Correo electrónico: daniel.rojas.lozano@gmail.com. ORCID: http:// orcid.org/oooo-0002-8902-1224

*** Antropóloga de la Universidad ICESI. Estudiante de Maestría en Antropología Visual, Facultad Latinoamericana de Ciencias Sociales, Ecuador. Correo electrónico: natalialopezcerquera@hotmail.com. ORCID: https://orcid.org/oooo0002-5238-7257

**** Artículo recibido el 02-10-2017 y aprobado 21-05-2018.
} 


\section{Cómo citar}

Trujillo Ospina, D.; RojAs-LozANo, D.; López CERQUera, N. (2018). Desbordamiento del extractivismo minero en Colombia: el caso de Suárez, Cauca. Revista CS, (26), 171-201.

DOI: https://doi.org/10.18046/recs.i26.2512 
Resumen

Abstract

Resumo

A partir del análisis del caso de Suárez, Cauca, se exponen tres momentos clave dentro del panorama minero de Colombia en el período 2002-2015: la feria de concesiones de 2002, el fortalecimiento de procesos organizativos, y el control territorial por parte de grupos armados y organizaciones criminales. En estos se evidencia el despliegue del discurso estatal neoliberal alrededor de la política minera y las especificidades que ha ido adquiriendo a partir de su implementación. Lo anterior en aras de establecer las particularidades que configuran la práctica minera en el país que, además, complejizan su clasificación como un caso de neo-extractivismo.

\section{PALABRAS CLAVE:}

Neo-extractivismo; Neoliberalismo; Feria de concesiones; Procesos organizativos; Suárez; Cauca

Based on the analysis of the case of Suárez, Cauca, three key moments in the Colombian mining scene from 2002 to 2015 are presented: the 2002 mining concession fair, the strengthening of organizational processes, and the territorial control on the part of armed groups and criminal organizations. These moments make evident the neoliberal state discourse deployment on the mining policy and the particular characteristics it has been acquiring since its implementation. All these elements serve to establish the peculiarities shaping the mining practice in Colombia, which also render its classification as a case of neo-extractivism more complex.

\section{KEYWORDS:}

Neo-extractivism; Neoliberalism; Concession fair; Organizational processes; Suárez; Cauca 
Com base na analise do caso do município de Suarez, no departamento del Cauca, na Colômbia, expõem-se três momentos-chave no panorama mineiro da Colômbia no período de 2002 a 2015: a feira de concessões de 2002, o fortalecimento dos processos organizacionais, e o controle territorial por grupos armados e organizações criminosas. Estes mostram a implantação do discurso do Estado neoliberal em torno da política mineira e as especificidades que adquiriu desde a sua implementação. $\mathrm{O}$ acima exposto, a fim de estabelecer as particularidades que compõem a exploração mineira no país que, além disso, complicam sua classificação como um caso de neoextrativismo.

PALAVRAS CHAVE:

Neo-extrativismo; Neoliberalismo; Feira de concessões, Processos organizacionais; Município de Suarez; Departamento del Cauca 


\section{Introducción}

El neo-extractivismo como práctica característica de varios países latinoamericanos en el siglo XXI ha generado un creciente interés académico. El caso colombiano no es ajeno a este; sin embargo, presenta ciertas particularidades que impiden clasificarlo como un caso de neo-extractivismo y que exigen de un análisis a nivel subnacional sensible a las diferencias sociales y culturales que se presentan al interior del país. Como se evidenciará en la segunda sección de este documento, una de las características del neo-extractivismo es la intervención estatal con propósitos redistributivos, intervención que ha sido fomentada desde gobiernos de izquierda y centro-izquierda. En el caso colombiano, aunque no es posible hablar de estos gobiernos, también se han observado dinámicas redistributivas con efectos igualadores (Bogliacino y Rojas-Lozano, 2017).

No obstante, las intervenciones en el sector primario, más precisamente en el minero-energético, no han sido dirigidas en este sentido, sino que, por el contrario, se han orientado a facilitar la llegada de capital privado a las actividades extractivas; aun cuando este capital se rige por lógicas ajenas a prácticas artesanales y comunitarias en donde el territorio y los recursos naturales trascienden el interés meramente económico. De esta manera, Colombia ha presenciado lo que aquí denominamos como el desbordamiento del extractivismo minero, que es el incremento en las concesiones y efectiva explotación de recursos minero-energéticos, aspectos que terminan sobrepasando las dinámicas productivas de comunidades como la de Suárez.

Este trabajo propone, como principal objetivo, establecer tres momentos clave dentro del panorama minero colombiano, tomando a Suárez, Cauca, como caso de estudio. Con esta selección será posible evidenciar el discurso estatal neoliberal alrededor de la política minera, así como los momentos que se han presentado en el marco de esta política: un primer momento en donde se facilita la llegada de capital privado a la gran minería y que se condensa en la feria de concesiones en el año 2002; un segundo en el que toma forma una serie de procesos organizativos que buscan hacer frente a la arremetida de las actividades extractivistas e ilegales, y un tercer momento, marcado por el auge de grupos armados ilegales.

El período de análisis que abarca esta investigación es desde 2002 hasta 2015. De esta manera, no solo se evidenciarán claramente los tres momentos mencionados, sino que también será posible relacionarlos con el contexto económico regional, enfatizando entonces en las características dadas durante y después del aumento 
en el precio internacional de las materias primas (primera década del siglo XXI). ${ }^{1}$ Todo esto permitió la implementación del modelo neo-extractivista en varios países de la región y la llegada de capital privado a la gran minería en el caso colombiano, en donde la caída en estos precios ha coincidido con el surgimiento de prácticas ilegales, tal como se expondrá más adelante.

Con el fin de dar cumplimiento al objetivo aquí propuesto, esta investigación se nutre de información de carácter cualitativo, cuantitativo y georeferenciada, de manera que sea posible definir analíticamente los tres momentos del panorama minero colombiano y sugerir algunas hipótesis para investigaciones futuras.

\section{Contexto regional y aproximación teórica}

Las materias primas han tenido un papel protagónico desde las primeras etapas de inserción de los países latinoamericanos en la economía mundial (Bértola y Ocampo, 2013). La implementación del modelo neoliberal a mediados de la década de 1990 no implicó un cambio de estructura económica que afectara el papel predominante de las materias primas dentro de las economías de la región; por el contrario, se fomentó un proceso de apertura económica que facilitara la llegada de inversión extranjera directa (IED) y diera mayor protagonismo al mercado, tanto en la asignación de recursos productivos como de precios. En este sentido, el protagonismo y relevancia de las materias primas dentro de las economías quedaría sujeto a la demanda internacional. El ascenso económico de China, al igual que el crecimiento de otros países extraregionales, incrementaría la demanda y precio de las materias primas, propiciando el desarrollo del extractivismo; es decir, de la explotación y exportación minera y petrolera (Gudynas, 2009) que, a su vez, se concebiría como medio para acelerar el crecimiento económico en los países ricos en estos recursos (Arsel, Hogenboom, y Pellegrini, 2016).

Ante los decepcionantes resultados de la apertura económica recomendada por el «Consenso de Washington» (Cornia, 2012), la región viviría lo que se ha denominado el «giro a la izquierda» (Panizza, 2005; Schamis, 2006), el cual estuvo caracterizado por la llegada al poder de gobiernos con esta orientación político-económica. No obstante esta variación, las economías continuarían vinculadas al mercado internacional y las materias primas seguirían siendo altamente demandadas. De hecho, Svampa $(2013,2015)$ argumenta que América Latina pasó del «Consenso de

1. En este sentido, los datos que se presentarán en las Tablas 1 y 2 muestran las variaciones porcentuales (delta) de los períodos 2000-2010 - auge en precio internacional de materias primas- y 2010-2015-disminución precio internacional de materias primas-. 
Washington» al «consenso de los commodities», caracterizado por la implementación masiva de proyectos extractivos para el incremento en las exportaciones a gran escala de materias primas: hidrocarburos, metales y minerales, productos agrícolas y bio-combustible. Este consenso marcará un acuerdo implícito sobre el carácter imprescindible de las actividades extractivas y las ventajas comparativas de ellas (Svampa, 2013).

El panorama internacional ha llevado entonces a mantener las prácticas extractivistas, pero esta vez con mayor participación del Estado, ya sea de manera directa -empresas estatales- o indirecta -asistencia financiera, infraestructura, subsidios-, dando lugar así al «neo-extractivismo» (Gudynas, 2012). Este último entendido como un extractivismo en donde los gobiernos distribuyen los excedentes generados en la exportación, destinándolos a gasto público, desarrollo de capital humano (Arsel, Hogenboom, y Pellegrini, 2016) y programas sociales dirigidos a combatir la pobreza (Burchardt y Dietz, 2014); pero donde, igualmente, se mantienen los negativos impactos sociales y ambientales derivados de esta actividad (Gudynas, 2009).

En este sentido, en el neo-extractivismo, a diferencia del extractivismo de las décadas del ochenta y del noventa, el Estado es más activo, impone mayores tasas de impuestos y regalías, y fomenta el desarrollo de empresas estatales en este campo. Sin embargo, se mantiene el interés exportador y la búsqueda de inversiones extranjeras; además, estos países mantienen su papel como tomadores de precios internacionales, reproduciendo una posición de subordinación en el mercado internacional. De hecho, los países latinoamericanos han terminado reprimarizando sus economías, dada la reversión de las estructuras comercial-exportadoras hacia el sector primario (Veltmeyer, 2012).

Ahora bien, el período en el que los gobiernos dieron el «giro a la izquierda $»^{2} \mathrm{e}$ implementaron políticas progresistas coincidió con el boom en el precio de commodities (primera década del siglo XXI). De aquí que sea difícil no vincular el neo-extractivismo con el posneoliberalismo, término que hace referencia al período mencionado (Van Teijlingen, 2016). El caso colombiano difícilmente puede ser considerado como un régimen posneoliberal, ${ }^{3}$ por el contrario, de acuerdo a Rojas (2009), el país ha presenciado la profundización del modelo económico neoliberal desde inicios del siglo XXI, lo cual se ha manifestado, entre otras cosas, en la introducción de

2. Argentina (Kirchner), Brasil (Lula da Silva), Bolivia (Morales), Ecuador (Correa), Chile (Bachelet), Uruguay (Vázquez) y Venezuela (Chávez).

3. En términos generales, el posneoliberalismo se refiere al período conocido como el «giro a la izquierda», el cual marcó la llegada de gobiernos de izquierda a diferentes países de la región. Para efectos de este artículo, la característica más relevante de los estados posneoliberales es la apropiación y distribución de la renta generada en la exportación de commodities. 
principios de productividad como criterios redistributivos del Estado. Igualmente, la profundización de este modelo económico ha permitido la expansión de las actividades extractivas mediante la llegada de inversión extranjera al sector, especialmente durante el boom en el precio del oro, en la primera década del siglo XXI (Vélez-Torres, 2014a).

Mientras que en varios países latinoamericanos se vincularon las prácticas extractivas con avances en política social, en el caso colombiano la política minera se enmarcó en discursos de productividad, eficiencia y tecnificación, los cuales, sin embargo, han sido matizados bajo el rótulo de responsabilidad social empresarial, aspecto impulsado mediante el Plan Nacional de Desarrollo vigente a la fecha. En este sentido, las políticas mineras del Gobierno colombiano pueden catalogarse como extractivas, debido a que promueven la extracción a gran escala de minerales no renovables, buscan atraer inversión extranjera y benefician a grupos y clases dominantes (Vélez-Torres, 2014b). De hecho, diferentes estudios han demostrado que las políticas extractivas del Estado colombiano terminan subsidiando la minería extranjera (Fierro, 2012; Rudas, 2012). Por ejemplo, la tasa de impuesto nominal que debían pagar las empresas en el sector minero energético entre los años 2002 y 2010 osciló entre el 33 y 38,5 por ciento sobre utilidades; sin embargo, tras exenciones y deducciones legales, terminaron pagando en promedio 27,6 por ciento (Rudas, 2012)

\section{El orden neoliberal en Colombia}

El orden neoliberal implantado durante los últimos veinte años en el país, junto con las reformas estructurales de la década de los noventa, propiciaron una reestructuración económica dentro del Estado colombiano. Desde el gobierno de Virgilio Barco (1986-1990) se consolidó la idea de «una necesaria reorientación de la política económica y de desarrollo» (Estrada, 2006, p. 149). Ya en el gobierno de Gaviria (1990-1994), el lema principal fue: «apertura económica y modernización del Estado», avanzando con ello hacia un proceso de desregularización de la economía. Todo ello incide en la consolidación de un modelo económico fuertemente influenciado por una lógica de libre mercado, donde se inserta al país en un nivel de competencia global.

Con el gobierno de Samper (1994-1998) y su plan nacional denominado el «salto social», se buscó implementar un modelo de desarrollo en el que la política social sería protagónica, dando relevancia al papel de la inversión en capital social. Sin embargo, durante este período se termina, finalmente, jalonando un régimen comercial abierto, que fomentó la participación privada en áreas tradicionalmente reservadas 
al Estado (Ocampo, 1995). A su vez, resultan siendo aumentadas considerablemente las dádivas a la inversión extranjera, lo que conllevó entonces a un mayor posicionamiento del modelo neoliberal.

Para el período presidencial de Andrés Pastrana (1998-2002) se decide dar comienzo a un fallido proceso de paz, el cual tuvo como motor de financiación el incremento en la oferta productiva exportable, resultado de la aplicación de medidas políticas y económicas orientadas a: 1) diversificar la oferta exportable de bienes, y 2) generar nuevos productos exportables (Departamento Nacional de Planeación, 1998). Pese a esto, el gobierno de Pastrana tuvo una etapa de recesión económica aguda en la que se asistió a la crisis del sector financiero. Esta crisis provocaría problemas en las finanzas del Estado, agravando así el déficit fiscal (Estrada, 2006).

En los dos gobiernos de Álvaro Uribe Vélez (2002-2006 y 2006-2010) se establecieron direccionamientos gubernamentales encaminados a incentivar las prácticas del libre mercado, la inversión y la propiedad privada. En efecto, la aplicación de cambios normativos, regulatorios e institucionales tendieron a propiciar el incremento en la participación privada en sectores tales como: infraestructura, minería y servicios públicos. Además, el discurso impulsado abogó por configurar «un país de propietarios donde todos se sientan dueños y responsables de un activo y un destino» (Departamento Nacional de Planeación, 2002, p. 19). Con la generación de condiciones para promover tanto la inversión privada como para dar garantías que asegurasen la propiedad privada, se pretendió sostener, en últimas, una política de seguridad que le brindara estabilidad y desarrollo al país.

Aunque, a grandes rasgos, las medidas económicas y políticas de los dos períodos presidenciales de Juan Manuel Santos (2010-2014 y 2014-2018) pareciesen seguir los mismos lineamientos erigidos por el gobierno predecesor, es preciso señalar que ambos se han distanciado en varios aspectos. Como tal, el gobierno de Santos no se ha sostenido propiamente bajo un modelo neoliberal de derecha y conservador, sino que más bien se ha mostrado públicamente como un proyecto encaminado a concertar con diversos actores bajo el presupuesto de unidad nacional, ${ }^{4} \mathrm{y}$ se ha apoyado en las capacidades tecnocráticas para administrar y sostener el conjunto de instituciones y procedimientos específicos de su gobierno. Esta estrategia de gubernamentalidad concibe el crecimiento económico a través de la generación de un alto nivel de productividad fundamentado en mayores inversiones, las cuales se direccionan hacia la competitividad empresarial y a la expansión de infraestructura 
física. Igualmente, se reitera la apuesta al desarrollo del sector minero-energético, visto como fuente para la equidad regional. ${ }^{5}$

\section{Ordenamiento de la práctica minera en Colombia}

Desde finales del siglo XX y principios del siglo XXI en Latinoamérica, especialmente en países como Chile, Ecuador y Perú, la minería ha sido un sector impulsado fuertemente dentro de las economías nacionales, al ser promovido como modelo principal de desarrollo (Göbel y Ulloa, 2014). Como afirman el Banco Mundial y la CEPAL, tan solo en 2009 «uno de los sectores con mayor recuperación y empuje en Latinoamérica, tras la crisis económica mundial, fue la minería, que se ha destacado por un auge de exploración y compra de proyectos mineros» (El Economista, 2010). Sin duda, Latinoamérica ha pasado a constituirse como una región dadora de materias primas y bienes de consumo que ha cumplido con satisfacer la demanda, cada vez más alta, de los países desarrollados (Svampa, 2012).

En Colombia, la minería ha sido una actividad económica que, históricamente, ha marcado las relaciones comerciales del país a nivel mundial (Colmenares, 1973). Desde el siglo XVIII, las indirectas y débiles relaciones del país con la economía global se basaron principalmente en las ventas de las regiones mineras del Cauca, Chocó y Antioquia, bajo un incipiente modelo minero exportador (Ocampo, 1984). Durante más de tres siglos, la minería neogranadina se ejecutó de manera simple y primitiva, especialmente mediante la sujeción de esclavos negros traídos desde África (Colmenares, 1973, 1979). En ciertos casos, la actividad minera se sostuvo bajo la modalidad de reales de minas, los cuales fueron propiedades de la Corona española; y en otros casos se desarrolló bajo minas de particulares que debían dar al gobierno virreinal una royalty o quinto real, el cual pasó a denominarse luego como regalía (Duarte, 2012b).

En sí, la gobernabilidad de la práctica minera sufrió serias transformaciones en el país y terminó por disponer nuevos ordenamientos territoriales para gobernar el suelo y el subsuelo de la nación, presuponiendo la acomodación estratégica de pautas de regulación y de promoción de la actividad extractiva. Tal como advierte Duarte (2012a), en un ejercicio cronológico minucioso de los principales cambios

5. El término de equidad regional es implementado en el gobierno de Juan Manuel Santos para hacer referencia al funcionamiento del nuevo Sistema de Regalías (en reemplazo del antiguo Fondo Nacional de Regalías), que en este caso implica una redistribución de los recursos que ingresen por regalías minero-energéticas para beneficio de la totalidad de las regiones del país, y no exclusivamente para las regiones productoras. 
en la legislación minera, durante el período de la conquista y la colonia se desató la consolidación de los conocidos distritos mineros. Luego, para la época republicana, se constituyó el principio de accesión, y ya para finales del siglo XIX se dispuso, propiamente, un modelo de ocupación.

En la primera mitad del siglo XX es establecido el modelo de concesión, dirigido a impulsar el desarrollo de la industria minera, y para la década del sesenta se constituyó un modelo de nacionalización de la explotación en el que se celebraban los contratos de asociación. A mediados de los años ochenta se creó una legislación de carácter mixto (pública y privada), en la que se diferenció por primera vez la exploración y explotación minera en materia de su magnitud y tecnificación. Finalmente, la Constitución de 1991 y la reestructuración del régimen económico bajo un modelo neoliberal facilitaría el advenimiento de proyectos extractivos a manos de intereses privados y empresas multinacionales, lo cual no se presentaría hasta 2002, año en el que incrementó sustancialmente la demanda y precio internacional de minerales y otros commodities.

Con el avance de dicho proyecto neoliberal, correlato de la globalización, el país abrió sus puertas a la inversión extranjera y la actividad minera estuvo encaminada bajo un modelo de enclave exportador (Duarte, 2012a). Tan solo entre 2002 y 2009, más de la mitad de los 50 ooo millones de dólares en Inversión Extranjera Directa (IED) llegó al sector minero y petrolero de Colombia (Mozzo, 2010). En relación con esto, el Plan Nacional de Desarrollo 2014-2018 advierte que el crecimiento del sector en el último cuatrienio

respondió en buena medida a un entorno de precios altos, que se reflejó en mayor IED, la cual pasó de USD\$ 4.961 millones en el año 2010 a USD\$ 8.281 millones en 2013, con una tasa de crecimiento promedio interanual de $46 \%$ (Departamento Nacional de Planeación, 2014, p. 105).

No obstante, la Contraloría General de la República (Garay, 2013) advierte sobre el inadecuado tratamiento en la distribución de la renta minera que presenta actualmente el país. La baja participación del Estado, tanto en coyunturas de precios normales como en bonanza de precios, sugiere la urgencia de revisar las tasas de participación pública en estas rentas y las polémicas medidas de exenciones, deducciones y descuentos generadas como estímulo a la inversión.

El modelo minero colombiano se ha basado principalmente en la extracción de minerales como el oro, el carbón y el níquel. Con el auge de los precios internacionales desatado en el año 2002 estos productos principales de exportación tuvieron picos sumamente altos. En lo que corresponde al oro, nunca antes se había extraído 
tanto de este mineral como se ha hecho desde 2012 (Revista Semana, 2013). Sin embargo, el panorama extractivista en Colombia parece estar cambiando, pues como se observa en la Tabla 1, la elevada variación porcentual entre los años 2000 y 2010 en indicadores como las exportaciones de metales y minerales y el precio del oro, ha sido seguida por una disminución en la variación en los inicios de la segunda década de este siglo.

\begin{tabular}{|l|l|}
\hline TABLA 1 & Panorama extractivista en Colombia \\
\hline
\end{tabular}

\begin{tabular}{|c|ccccccc}
\hline $\begin{array}{c}\text { Exp. productos } \\
\text { primarios }\end{array}$ & $\begin{array}{c}\text { Exp. metales } \\
\text { y minerales }\end{array}$ & $\begin{array}{c}\text { Regalías minerales } \\
\text { distribuidas }\end{array}$ & $\begin{array}{c}\text { Precio oro } \\
\text { (USD/oz) }\end{array}$ \\
\hline Delta & Delta & Delta & Delta & Delta & Delta & Delta & Delta \\
Oo-10 & $\mathbf{1 0 - 1 5}$ & $\mathbf{0 0 - 1 0}$ & $\mathbf{1 0 - 1 5}$ & $\mathbf{0 0 - 1 0}$ & $\mathbf{1 0 - 1 5}$ & $\mathbf{0 0 - 1 0}$ & $\mathbf{1 0 - 1 5}$ \\
\hline $226,0 \%$ & $-9,4 \%$ & $147,6 \%$ & $-20,6 \%$ & $754,8 \%$ & $36,4 \%$ & $338,4 \%$ & $2,0 \%$ \\
\hline
\end{tabular}

Fuente: elaboración propia con base en datos de Cepal-Stat, Banco Mundial, SIMCO y Bolsa de Metales de Londres (LME) y Kitco. Los delta corresponden a las variaciones porcentuales entre los años 2000-2010 y 2010-2015. Las exportaciones de productos primarios se refieren a las variaciones de millones de dólares en bienes FOB; los productos primarios incluyen productos alimenticios y animales vivos; bebidas y tabaco; materiales crudos no comestibles (excepto combustibles); combustibles y lubricantes, minerales y productos conexos; aceites, grasas y ceras de origen animal y vegetal; mercancías y operaciones no clasificadas en otro rubro. Las exportaciones en metales se refieren a la variación en la participación de este rubro dentro del total de mercaderías; los minerales y metales comprenden los productos incluidos en las secciones 27 (abonos y minerales en bruto), 28 (menas y desechos de metales) y 68 (metales no ferrosos) de la CUCI. Las variaciones en regalías se refieren a millones de pesos.

Con la implementación del modelo de enclave exportador, no solo la economía nacional se abrió a la lógica del libre mercado, sino que paralelamente se consolidaron en las últimas dos décadas procesos de flexibilización en los marcos normativos estatales. Tal como lo expone el Centro de Estudios para la Justicia Social «Tierra Digna» (2011), la inflexión extractivista adoptada por países como Colombia ha producido repercusiones de tipo laboral (en la reducción de costos de producción a favor de empresarios), de tipo fiscal y tributario (en la reducción de gravámenes, entendiendo que, durante el período de 2007 a 2011, el Estado llegó a recibir solo 16 centavos por cada dólar generado por este sector), y de tipo ambiental (en el poco cumplimiento del engranaje normativo orientado a garantizar la conservación de las zonas de protección ambiental), entre otros.

Ya con la reforma al Código de Minas de 1988, impulsada dentro del primer gobierno de Álvaro Uribe Vélez, se buscó introducir «una gobernabilidad minera que ampliara las facilidades para la inversión y explotación extranjera sobre los recursos mineros de la nación. La Ley 685 del 2001 [...] se edificaría-entonces- siguiendo los antecedentes del proyecto de Aramburo en 1996» (Duarte, 2012a, p. 25). 
No obstante, este nuevo código es el reflejo de fuertes contradicciones y tensiones en el plano normativo, administrativo e interpretativo del modelo minero en el país. El código no solo supone una reducción del papel del Estado en cuanto ente regulador, promotor y fiscalizador dentro del sector; sino que implica, además, que la minería se configure como una actividad prioritaria en zonas donde pueden existir otras actividades, al declararla como actividad de «utilidad pública e interés social». ${ }^{6}$ Del mismo modo, se genera flexibilización en los procedimientos para acceder a los títulos mineros para las empresas con grandes capitales, se amplían las condiciones para prorrogar los contratos, se eliminan los rangos en los que se enmarcan las actividades mineras y se establecen procedimientos genéricos para la pequeña, mediana y gran minería, obligando finalmente a los dos primeros a competir en las mismas condiciones que los proyectos a gran escala. ${ }^{7}$ En cuanto a su implicación para las poblaciones étnicas, el código consagra las Zonas Mineras Especiales, las cuales se conciben como la forma legal para dar inicio a un proceso de titulación bajo un contrato de concesión en el que tienen prelación las comunidades indígenas y negras. Pese a ello, las altas exigencias que implica la tramitación legal ha supuesto un fuerte obstáculo para que estas comunidades puedan titular bajo esta modalidad.

Durante el gobierno del presidente Juan Manuel Santos se generaron reordenamientos administrativos y jurídicos que han tenido gran implicación para el sector minero, dado que han intervenido directamente en la naturaleza de las instituciones y en la manera como se regula y planifica la práctica como tal. Dentro de estos reordenamientos sobresalen la creación de la Agencia Nacional de Minería y la Autoridad Nacional de Licencias Ambientales (ANLA), la declaración de inexequibilidad de la Ley 1382 de 2010 por parte de la Corte Constitucional, la constitución del Sistema General de Regalías (SGR), el cambio de naturaleza jurídica de Ingeominas y su transformación en el Servicio Geológico Colombiano (SGC), la determinación de Minerales de Interés Estratégico para el país, la reorganización del Ministerio de Minas y Energía y sus nuevas funciones, y la adopción del Plan Nacional de Ordenamiento Minero, entre los más significativos.

Desde luego, otro elemento trascendental en estas recientes transformaciones de la gobernabilidad minera ha sido la política de Estado del actual Gobierno, de-

6. La Ley 685 de 2001 decreta, en el Artículo 13, que: «En desarrollo del artículo 58 de la Constitución Política, declárese de utilidad pública e interés social la industria minera en todas sus ramas y fases. Por tanto podrían decretarse a su favor, a solicitud de parte interesada y por los procedimientos establecidos en este Código, las expropiaciones de la propiedad de los bienes inmuebles y demás derechos constituidos sobre los mismos, que sean necesarios para su ejercicio y eficiente desarrollo».

7. Para una ampliación de estos puntos, véanse los informes de la Contraloría General de la República en Garay (2013, 2014a, 2014b) 
nominada «Visión 2019: Colombia como un país minero». Esta política ha tenido como objetivo principal poner en marcha una «serie de acciones que favorecieron las inversiones extranjeras y llevaron a la creación de distritos mineros en buena parte del país. Estas acciones han atraído millones de dólares, fundamentalmente, para exploración minera» (Idárraga, 2010, p. 1). Como reporta la Contraloría General de la República, debido a esta reciente determinación política, la exportación de carbón se ha duplicado, mientras que la del oro ha llegado a cuadruplicarse. No obstante, el modelo de enclave exportador adoptado en el país no ha generado mayor valor agregado, puesto que estos minerales son exportados crudos casi en su totalidad ( $99 \%$ el oro, y entre 92 y 95\% el carbón), «razón por la cual no establecen encadenamientos productivos y, por lo tanto, no dinamizan directamente la economía, al menos de manera apreciable respecto al valor explotado» (Cabrera y Fierro, 2013, p. 98).

El fuerte interés del Estado por impulsar la práctica minera como fuente de desarrollo y crecimiento económico ha hecho que, en definitiva, la minería en Colombia se haya caracterizado por una serie de impactos que se han relacionado con «el carácter intensivo, prolongado y sistémico de las actividades extractivas y de las externalidades que generan en los territorios la exploración y explotación de minas» (Vargas, 2013, p. 57). Tales impactos cada vez son de mayor alcance y se materializan en el uso intensivo de una mayor proporción del suelo y subsuelo nacional. Este acaparamiento del suelo y del subsuelo con la entrega indiscriminada de concesiones mineras ha provocado serias afectaciones a las comunidades étnicas y culturales que se asientan en las zonas rurales del país.

El modelo extractivista imperante no solo ha afectado los niveles de acceso y uso de los recursos naturales por parte de estas poblaciones, sino que además ha implicado el despojo de sus tierras tradicionales, la ruptura de los tejidos sociales, la transformación de sus prácticas ancestrales y estilos de vida, la violación del derecho a la consulta previa para lograr un consentimiento libre, previo e informado (Centro de Estudios para la Justicia Social «Tierra Digna», 2011), y la vulneración del derecho a la vida con la llegada de actores armados y bandas criminales.

\section{El caso de las comunidades negras de Suárez, Cauca}

El municipio de Suárez se encuentra ubicado al margen de la cordillera occidental, sobre el valle geográfico del río Cauca. Este territorio hace parte de la región que comprende el norte del departamento del Cauca, junto con los municipios de: Puerto Tejada, Miranda, Villa Rica, Padilla, Guachené, Corinto, Caloto, Toribío, Jambaló, Caldono, Santander de Quilichao y Buenos Aires (ver Mapa 1). 


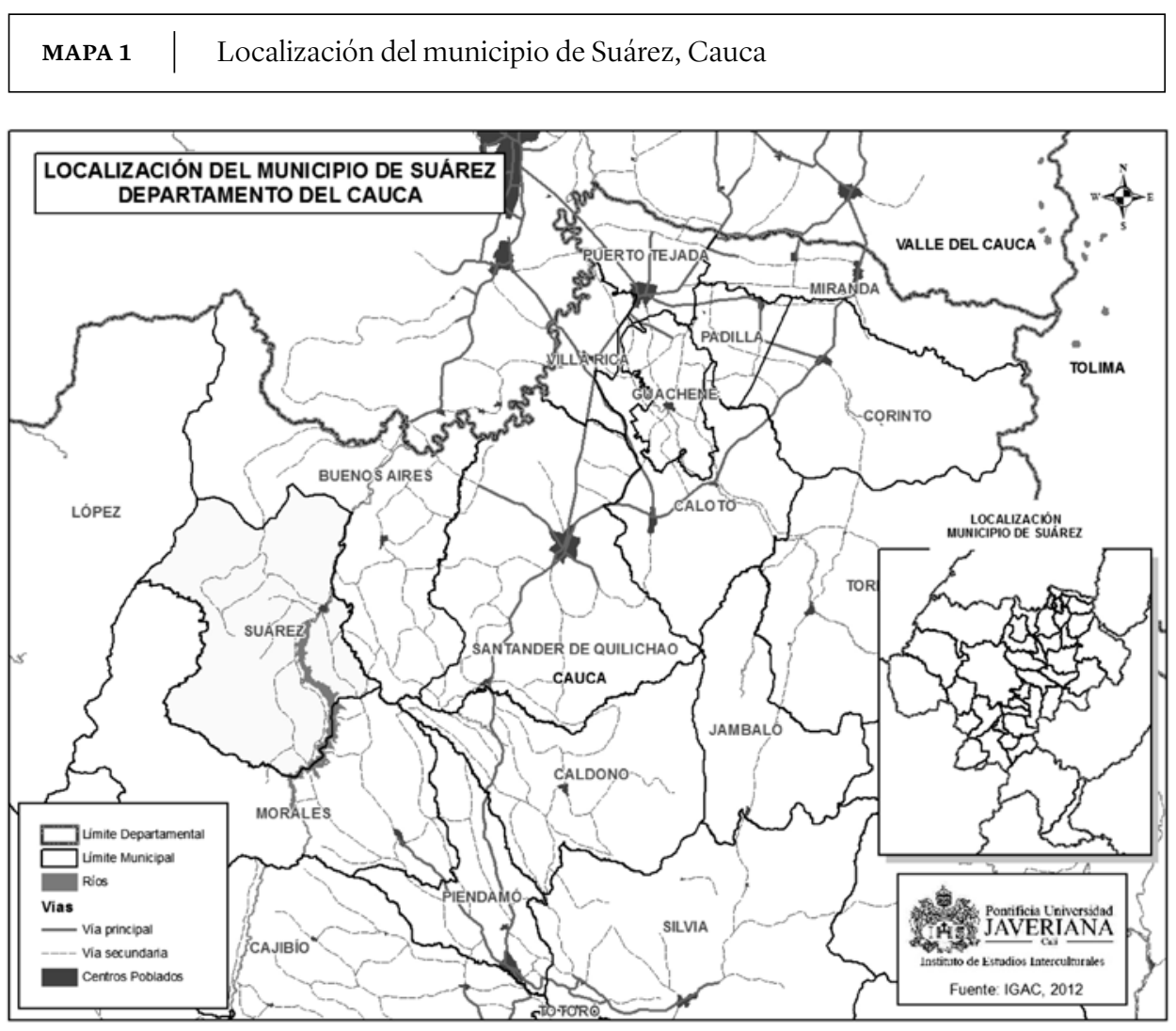

Fuente: Instituto de Estudios Interculturales, 2017.

Suárez se ha caracterizado históricamente por ser un municipio minero, ya que entre finales del siglo XVI y comienzos del XVII se registra la primera llegada de negros esclavos traídos desde África como mano de obra para las minas de Gelima y las riberas del río Ovejas (Ararat et al., 2013). Por tanto, y tal como registra el censo del DANE (2005), la población asentada en este municipio es mayoritariamente afrodescendiente.

$\mathrm{Al}$ ser una zona primordialmente minera, Suárez se ha convertido en escenario de fuerte interés para el despliegue de proyectos extractivos por parte de diferentes empresas, inversionistas y grupos al margen de la ley. De esta manera, los múltiples sucesos que han tenido lugar en este territorio han estado ligados a problemáticas de violencia, desigualdad y exclusión, las cuales son potenciadas, al mismo tiempo, por un modelo de desarrollo económico de enclave, el cual carece de valor agregado 
y termina por reproducir las fuertes brechas de desigualdad en el sector rural. Tales problemáticas, en últimas, son las que han venido afectando de manera considerable a estas poblaciones campesinas y étnicas que históricamente se han asentado en estas zonas ricas en recursos minerales no renovables.

\section{La desmedida feria de concesiones minera}

Posterior a la implementación del Código de Minas de 2001, se dio un crecimiento importante en la asignación de concesiones mineras, bajo el soporte de disposiciones como las establecidas en su Artículo 14, el cual señala que «únicamente se podrá constituir, declarar y probar el derecho a explorar y explotar minas de propiedad estatal, mediante el contrato de concesión minera, debidamente otorgado e inscrito en el Registro Minero Nacional» (Congreso de la República de Colombia, 2001). ${ }^{8}$

A partir del año 2002, se despliega y consolida alrededor de todo el país una feria de concesiones que atrajo no solo a empresas extranjeras interesadas por invertir en el país, sino también a distintos actores ilegales que vieron en esta actividad la oportunidad para adquirir cuantiosas ganancias. Desde entonces casi todo el subsuelo de la nación fue concesionado a firmas nacionales y empresas multinacionales,

7.0oo títulos mineros en todo el país; 1.800 en la Amazonía, la mayoría reserva forestal; 44 en Parques Nacionales; 13 en el municipio de Suárez. La concesión de títulos se ha hecho sobre zonas protegidas como páramos, humedales, resguardos y, claro está, comunidades negras (Molano, 2010).

En contraste con la asignación de títulos para las prácticas mineras a gran escala, según las cifras del Catastro Minero Colombiano, «a julio de 2012, de la totalidad de tierras de comunidades negras reconocidas por las autoridades competentes, el 6,02\% cuenta con título minero y el $16,50 \%$ se encuentra solicitado para el desarrollo de actividades mineras» (Cabrera y Fierro, 2013, p. 96). Estos datos guardan estrecha relación con las exigencias establecidas dentro del Código Minero para asignar las Zonas Mineras Especiales a comunidades étnicas. De acuerdo con Vélez-Torres y Ruiz-Torres,

la mayoría de las comunidades afrodescendientes que han tenido la minería como medio de producción y reproducción en los valles inter-andinos no cuentan con territorio colectivo. Por consiguiente, sus opciones para acceder a la titulación especial

8. Actualmente, el ente encargado para la inscripción y el otorgamiento de títulos es la Agencia Nacional de Minería. 
minera están condicionadas a la densa burocracia que afrontan en la titulación de tierras; posteriormente, también afrontan las barreras relacionadas con los criterios de productividad, eficiencia y tecnificación de la minería tradicional (2015, p. 11).

Las titulaciones que se han expedido en el marco de esta feria de concesiones se caracterizan por haber sido otorgadas «sin ningún tipo de control, se violaron los derechos de comunidades indígenas y afrodescendientes, y se permitió el acaparamiento de títulos» (Hincapié y López, 2016, p. 136). En el año 2001, diferentes medios de comunicación pusieron en evidencia la falta de regularización y fiscalización de estos títulos por parte de las entidades estatales y gubernamentales encargadas de administrar y otorgar estas concesiones a particulares y empresas mineras. Tanto el Ministerio de Minas y Energía como Ingeominas fueron el centro de escándalos que ponían a la luz un sinnúmero de irregularidades institucionales.

En mayo de 2011, el ministro de Minas y Energía, Carlos Rodado, manifestó en una rueda de prensa que:

en el sector minero colombiano se han detectado situaciones preocupantes como superposición de títulos mineros en áreas de páramos y parque naturales, especulación de títulos, anomalías en la contratación y la fiscalización minera, expedición de títulos mineros con requisitos mínimos que no garantizan capacidad técnica y económica para el desarrollo de una minería responsable, y violación de los derechos de las comunidades mineras tradicionales (Ministerio de Minas y Energía, 2011).

Para el año 2011 había represadas 19629 peticiones de títulos mineros, de las cuales, en 2014, estaban pendientes 4115; sumándole las 4724 nuevas solicitudes realizadas tras la reapertura de la ventanilla minera, en 2013. Para actuar con estos procesos, tras la ratificación de potestad del Estado sobre los recursos del subsuelo, se fijó en 2014 la necesidad de acordar medidas para la protección de cuencas hídricas y garantizar el desarrollo social, económico y cultural de las comunidades; directrices a cargo del Ministerio de Minas y Energía (Ahumada, 2014).

En el año 2015, tras la Acción de Nulidad presentada por el Centro de Estudios para la Justicia Social «Tierra Digna», en la que se cuestionó la legalidad de las decisiones del Gobierno en relación con las Áreas Estratégicas Mineras ${ }^{9}$-las cuales se traslapaban con territorios de comunidades étnicas y campesinas, al igual que con ecosistemas estratégicos tales como la Amazonía, el Chocó biogeográfico y el

9. Las Áreas Estratégicas Mineras fueron delimitadas por el Gobierno nacional para la ejecución de las labores de exploración y explotación de minerales a gran escala. Dichas zonas serían adjudicadas a empresas privadas a través de procesos de licitación pública (Centro de Estudios para la Justicia Social «Tierra Digna», 2015). 
Macizo Colombiano-, la Sección Tercera del Consejo de Estado ordenóla suspensión de las resoluciones que soportaban la creación de 16 Áreas Estratégicas Mineras, argumentando la violación al derecho a la consulta previa de comunidades étnicas (Centro de Estudios para la Justicia Social «Tierra Digna», 2015).

Por su parte, la Corte Constitucional, en el año 2016, cuestionó los procedimientos para la aprobación de títulos mineros, lo que trajo consigo la petición de intervención por parte del Congreso. Además, el Alto Tribunal ordenó que se debía establecer un procedimiento para asegurar la participación ciudadana en los procesos de exploración y explotación minera (Revista Semana, 2016).

De la asignación desmedida y desregularizada de títulos mineros se han derivado múltiples consecuencias, que para este caso terminaron afectando la gobernabilidad de las instituciones, tanto a nivel local como regional, pues les fueron impuestas decisiones tomadas en instancias centrales y extraterritoriales (Cabrera y Fierro, 2013, p. 110). Lo anterior considerando que las titulaciones y prácticas extractivas en la mayoría de casos no se han realizado en consonancia con los procesos y dinámicas de ordenamiento territorial y ambiental, perjudicando con ello la gobernabilidad de las comunidades y de las mismas instituciones locales y regionales.

Ante este panorama, las acciones que buscan proteger los territorios del arribo de estos proyectos extractivos no se han hecho esperar, entrando a configurar «un escenario de conflicto y disputa por la defensa del territorio y los bienes comunes» (Hincapié y López, 2016, p. 136). En sí, la feria de concesiones, tal como lo aseveran Hincapié y López (2016), ha agudizado la criminalización y represión de las acciones colectivas de las comunidades; potenciando, también, los conflictos ya existentes y afectando las relaciones entre las mismas comunidades. Considerando, además, que ante la limitada acción institucional, deben enfrentarse no solo con las empresas mineras protegidas por los gobiernos, sino también a los actores armados y organizaciones criminales que refuerzan las dinámicas de explotación desmesurada dentro de sus territorios.

En el momento en que el Estado facilitó la consecución de concesiones mineras, en 2002, inició la intervención de diferentes multinacionales en los territorios. En el caso del departamento del Cauca, una investigación del Instituto de Estudios Interculturales (2014) reveló que, para 2012, en el Cauca habían sido otorgados 241 títulos para la exploración de 350 mil hectáreas, y 652 solicitudes se encontraban en marcha; cifras que comprometen el $50 \%$ de este territorio.

En concreto, en el municipio de Suárez, Cauca, fueron adjudicados 13 títulos a particulares y empresas para la extracción de minerales, especialmente oro. Se destacan los otorgados a Héctor Jesús Sarria, sobre un área que ha sido trabajada desde hace más de 374 años por el consejo comunitario de La Toma, en el que se 
agrupan alrededor de 1100 familias (Molano, 2010). De las 7000 hectáreas que tiene el corregimiento de La Toma, Ingeominas le otorgó a Sarria 99, además de 6507 metros cuadrados de la mina que está localizada en la quebrada La Turbina, del río Cauca; dicho título fue autorizado para explotar oro por diez años prorrogables (Bolaños, 2012).

Igualmente, una de las multinacionales con mayor injerencia dentro de estos territorios ha sido la AngloGold Ashanti. Esta compañía minera ha llevado a cabo la prospección y exploración en 20 departamentos y 340 municipios del país, sumando alrededor de 11 millones de hectáreas, en miras a extraer, además de oro, minerales como zinc, manganeso, plata, cobre y molibdeno. En Suárez fueron solicitadas 26465 hectáreas, de las cuales ya han sido concesionadas 350 en todo el municipio (Buenaventura y Trujillo, 2011, p.27). En el Mapa 2 se puede observar la vasta extensión del territorio que está siendo comprometida para las actividades mineras en el municipio; de las cuales, además, se hace evidente el predominio de la minería ilegal.

MAPA 2 Actividad minera en el municipio de Suárez, Cauca

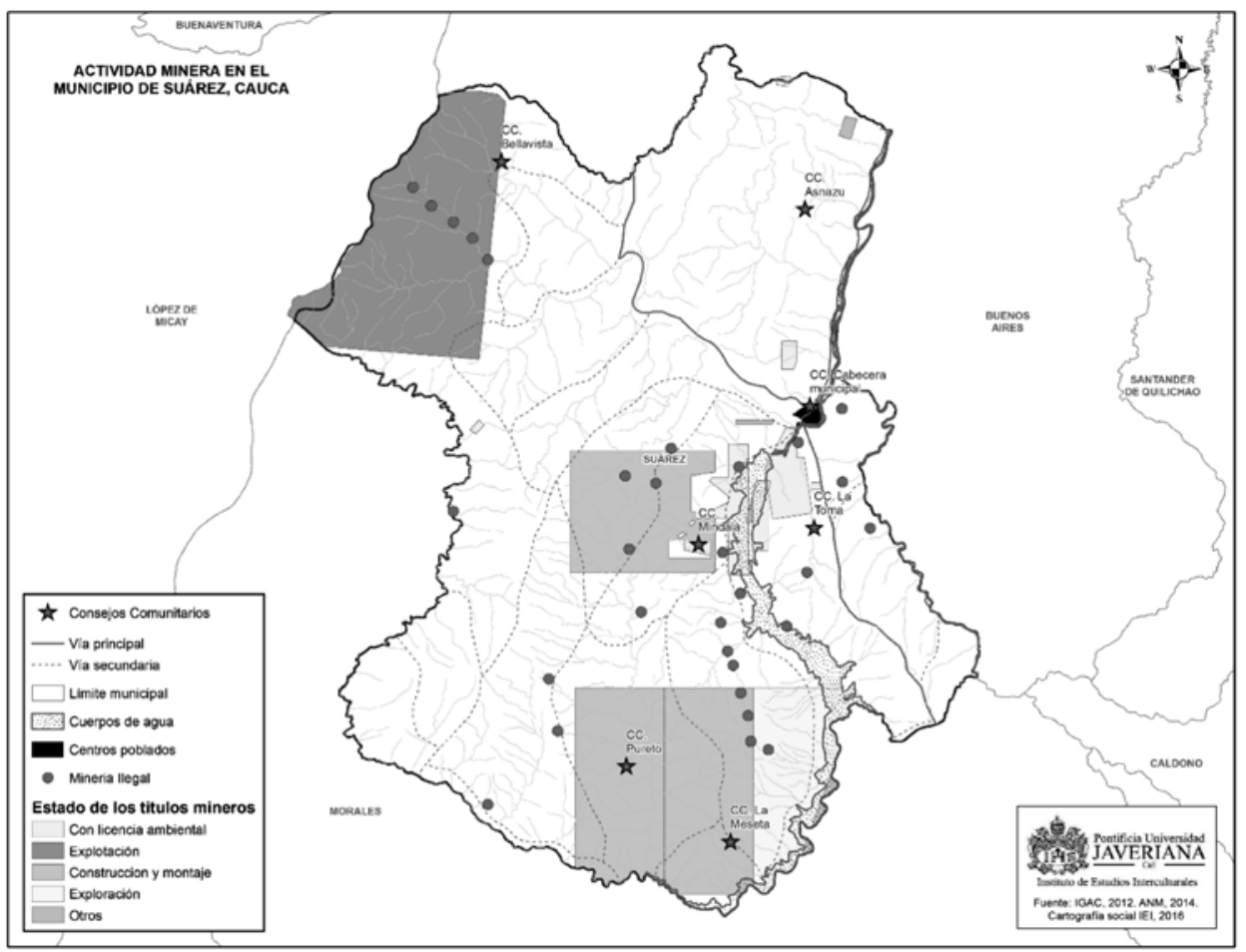


Así las cosas, es posible advertir cómo en este tipo de espacios extractivos, una vez es ejecutada la feria de concesiones como producto de una iniciativa estatal, las dinámicas de defensa territorial de la comunidad negra entran en disputa con respecto a las pretensiones del Estado, quien le da prioridad a los intereses privados e inversiones multinacional y transnacional, con el respaldo de instituciones como el Ministerio de Minas y Energía, Ingeominas y la misma legislación minera. Muestra de ello son las dificultades que ha tenido que enfrentar la comunidad del corregimiento minero de La Toma en Suárez, donde a pesar de que su práctica artesanal data de siglos atrás, no han logrado que su territorio sea reconocido como Zona Minera Especial, pues aún no se les adjudica la titulación colectiva del territorio (Vélez-Torres, 2014b, p. 54).

Por otro lado, el arribo de las compañías interesadas en la explotación minera a gran escala -con el que se acrecentaron las dinámicas de despojo territorial y la falta de garantías por parte del Estado y de las mismas empresas-, contribuyó al desbordamiento de la problemática que vienen afrontando estas comunidades negras desde hace varios años, exacerbándose la disputa por el territorio. Por estas razones se identifica, a lo largo de los años, el surgimiento de experiencias organizativas locales con el ánimo de configurar mecanismos efectivos para la defensa territorial.

\section{Los procesos organizativos y su latente lucha ante la arremetida extractivista}

Diferentes estudios han puesto el énfasis en el efecto de la titulación colectiva sobre los procesos organizativos de las comunidades involucradas (Vélez, 2011; Offen, 2003). Sin embargo, aquí se busca resaltar el efecto de la gran minería sobre dichos procesos, los cuales han comenzado a girar alrededor de la defensa territorial (Sañudo et al., 2016; Svampa, 2012). En este sentido, se destaca que entre enero de 2001 y diciembre de 2011 se registraron 274 acciones sociales colectivas relacionadas con conflictos mineros y petroleros, las cuales han aumentado de manera constante desde 2008 (Rivera et al., 2012). Este incremento sostenido, según Vélez-Torres y Ruiz-Torres (2015), puede ser consecuencia de las implicaciones del cambio en la legislación minera en 2001 y, a la vez, deberse al desarrollo de capacidades organizativas; agregándole a ello el liderazgo previo de organizaciones de base, asociaciones comunitarias y figuras étnico-territoriales para manifestarse en contra de los graves y profundos impactos de este extractivismo a la luz de una feria de concesiones desmedida. 
Los conflictos generados por la minería pueden ser resultado de la falta de participación o representación de las comunidades locales, así como de la exacerbación de sus exigencias sociales y culturales. Estas comunidades, a medida que ven amenazada la salud o sustento, son más propensas a desarrollar procesos de resistencia (Conde, 2017). Además, los movimientos que han surgido en torno a las prácticas extractivistas han buscado una reformulación de la política minera, de manera que se reconozca el ordenamiento territorial (Rivera et al., 2012).

Ahora bien, de acuerdo a Bebbington (2012), la fase en la que se encuentre la explotación minera afectará las demandas y objetivos de la comunidad: cuando el proyecto minero se ha estado ejecutando por un largo período de tiempo, es más probable que las comunidades busquen concesiones o compensaciones; mientras que si el proyecto se encuentra en una fase previa a la ejecución, la comunidad se opondrá y confrontará al proyecto. En el caso aquí abordado es posible observar la segunda dinámica, que a su vez refleja cómo las políticas extractivas implementadas durante los gobiernos de Uribe y Santos rivalizan con los derechos étnicos de comunidades locales, establecidos en la Constitución de 1991.

En este sentido, es preciso resaltar el papel que ha jugado el Consejo Comunitario como figura étnico-territorial dentro de estas áreas en las que se asienta población negra. En especial, es de resaltar el protagonismo que ha adquirido en las últimas décadas el Consejo Comunitario de La Toma, ${ }^{10}$ constituido en 1994 en el corregimiento que lleva su mismo nombre. Como tal, el Consejo de La Toma se estableció como estrategia de defensa del territorio y los derechos humanos; siendo igualmente una figura clave para dar a conocer las problemáticas que enfrenta la comunidad ante la sociedad nacional e internacional, particularmente sobre aquellas derivadas de los procesos mineros y la defensa de sus prácticas mineras de tipo ancestral (Buenaventura y Trujillo, 2011). En 2005, se realizó la primera asamblea para abordar el tema de la concesión de títulos mineros, en el año 2004, a la multinacional AngloGold Ashanti. Igualmente, esta asamblea permitió fortalecer los lazos entre los miembros de la comunidad, la cual llevaría a cabo la primera marcha afro hacia las instalaciones de la Corporación Autónoma Regional del Valle del Cauca (CVC), con sede en Cali (Buenaventura y Trujillo, 2011). Con esta marcha se buscó

10. La conformación del Consejo Comunitario tiene sus antecedentes en el proceso que emprendió la comunidad para detener el trasvase del río Ovejas, enmarcado en la extensión de la represa La Salvajina. Su consolidación y fortalecimiento coincide con las luchas en contra de los proyectos mineros a gran escala que para ese entonces -facilitados por la feria de concesiones- buscaban instaurarse en los territorios (Ararat, et al., 2013, p. 167-168). 
denunciar y visibilizar la llegada de la gran minería y sus implicaciones negativas para los derechos de las comunidades de Suárez.

Posteriormente, en el año 2010, se realizó la Mesa Minera en Suárez, donde confluyeron representantes del Gobierno, indígenas y afrodescendientes. En esta mesa se buscó denunciar las amenazas, asesinatos y desalojos de los habitantes de la zona, especialmente de aquellos que continuaban alertando sobre la llegada de multinacionales que, mediante prácticas legales, facilitadas por la política minera, comenzarían a realizar despojos de tierras. Adicionalmente, las demandas de la comunidad de Suárez reflejaban el incremento de dinámicas violentas e ilegales en torno a prácticas mineras.

Otro de los procesos organizativos que ha surgido en respuesta a ciertas prácticas mineras es la Movilización de las Mujeres Afrodescendientes por el Cuidado de la Vida y los Territorios Ancestrales. Este proceso es consolidado en el año 2014 para defender los territorios colectivos del norte del Cauca de la minería ilegal (Sañudo et al., 2016). Las mujeres partícipes de esta movilización pidieron al gobierno el cumplimiento de la sentencia T-1045 de 2010, la cual exige la realización de un proceso de consulta previa antes de otorgar licencias de explotación minera. Esta sentencia marca un punto de quiebre en el avance extractivista en territorios habitados por grupos étnicos, pues, además de proteger el derecho a la consulta previa, concibe como una violación a la integridad cultural y social el otorgar títulos mineros sin la aprobación de las comunidades afectadas.

Los procesos organizativos dentro de Suárez no solo se han facilitado debido a la identidad compartida de quienes en ellos participan, sino que han logrado articularse al esquema legal-institucional que respalda estrategias como el Consejo. Sin embargo, como se evidenciará en la siguiente sección, estos procesos han empezado a ser atacados mediante acciones violentas de grupos ilegales, dando lugar a la configuración de un tercer momento clave dentro del panorama minero.

\section{Control territorial de grupos armados y organizaciones criminales.}

Otro momento importante dentro del panorama minero del país se vincula a la incursión de grupos armados y organizaciones criminales. Este fenómeno guarda relación con dos fines: de un lado, ejercer control sobre territorios mediante la violencia y el desplazamiento de poblaciones, con el objetivo de dar espacio a la gran minería 
(Vélez- Torres, 2014b). Por otro, la obtención de recursos a través del fomento y la práctica de actividades extractivas de manera ilegal. ${ }^{11}$

Un informe de la Contraloría reportó que, en 151 municipios de 25 departamentos, confluyen la minería ilegal y los grupos armados. Asimismo, un reciente estudio de la Fundación Ideas para la Paz señala la presencia de bandas criminales en la mitad de los municipios productores de oro. Bajo esta dinámica, se estima que dentro de las unidades de producción minera sin títulos ni licencias con las que cuenta el Ministerio de Minas, 9044 unidades se encuentran tomadas por grupos armados (Negrete, 2013, p. 26).

Dentro de la relación entre la minería ilegal y los grupos armados se han identificado vínculos con prácticas de contrabando y lavado de activos. Al respecto, la Contraloría refiere que los actores armados utilizan las minas como «fachada o importan oro de contrabando para hacerlo pasar como producción local o importan maquinaria para la minería comprada con dólares provenientes del narcotráfico» (Pardo, 2013, p. 178). En muchos casos, los recursos derivados de estas prácticas son destinados a la financiación de grupos armados y organizaciones criminales, según información de la Dirección de Carabineros y Seguridad Rural de la Policía (Revista Semana, 2014).

Inicialmente, en Suárez la extracción ilegal e informal de oro se dio a partir del arribo de foráneos, jalonada por las alzas en el precio del oro a nivel internacional durante el primer lustro de la década de 2000. Entre 2005 y 2007 arribaron cerca de 400 mineros a la zona, procedentes principalmente de El Bagre (Antioquia) y del Urabá Chocoano ${ }^{12}$ (Bolaños, 2012). Sin embargo, en la actualidad, la operación ilegal se ha concentrado en manos de grupos armados y organizaciones criminales.

En el municipio, la presencia de las Autodefensas Unidas de Colombia tuvo su punto más álgido entre los años 2000 y 2004, lo que trajo consigo acciones violentas contra la comunidad. Después de esta incursión, la disputa por el control minero dentro de estos territorios se ha dado entre las FARC y los grupos paramilitares Águilas Negras y Rastrojos (Vélez-Torres y Ruiz-Torres, 2015, p. 11). A raíz de la presencia de dichos actores armados en este territorio del norte del Cauca, para 2011, el diario El Espectador (2011) informó que la comunidad se vio obligada a detener

11. La minería ilegal se concentra, principalmente, en las riberas de los ríos, pues, al utilizar chorreo a presión, requiere de grandes cantidades de agua. Utilizan motobombas, retroexcavadoras, dragas y químicos altamente contaminantes como el cianuro y el mercurio (Defensoría del Pueblo, 2015).

12. Estas dinámicas derivaron en conflictos con los habitantes de la zona, en gran medida por implementar métodos extractivos que van en contravía del tipo de práctica ancestral que los pobladores han realizado durante décadas; a lo que se le suma el gran impacto ambiental que genera (Bolaños, 2012). 
sus prácticas de minería artesanal, las cuales históricamente han representado el sustento económico y el legado cultural de alrededor de 1300 familias.

Tanto líderes como representantes del Consejo Comunitario de La Toma se enfrentan a constantes amenazas y, en muchos casos, han tenido que desplazarse del territorio; tal como ocurrió en el año 2015, cuando fue amenazado el presidente del Consejo Comunitario, Sabino Lucumí, y los líderes Francia Márquez, Eduar Mina y John Jairo Valverde, al denunciar y enfrentar las prácticas mineras ilegales desarrolladas y financiadas por el grupo criminal Águilas Negras (Silva, 2015). Igualmente, integrantes de la comunidad han sido asesinados por parte de grupos armados paramilitares o bandas armadas criminales (BACRIM).

Para el año 2010, en la mina de El Ato fueron asesinados nueve mineros. El siguiente año un minero fue secuestrado, otro fue herido y diez resultaron amenazados. En los inicios de 2013, en la mina Fuego Verde, fueron asesinados tres mineros más (Vélez-Torres, 2014b, p. 55). Frente a este tipo de sucesos, los miembros del Consejo Comunitario han exigido en diversos escenarios la intervención del gobierno para «acabar con la minería 'criminal', que pone en riesgo su vida e integridad y vulnera sus derechos como grupo étnico, y, de otra parte, solicitan concesionarles el derecho de la explotación del oro en su territorio para su subsistencia» (Defensoría del Pueblo, 2015, p.45).

\begin{tabular}{l|l} 
TABLA 2 & Desplazamientos y homicidios en Suárez, Cauca
\end{tabular}

\begin{tabular}{|c|ccc}
\hline \multicolumn{2}{|c|}{ Personas desplazadas } & \multicolumn{2}{c|}{ Tasas homicidios } \\
\hline Delta $00-10$ & Delta 10-13 & Delta oo-10 & Delta 10-13 \\
\hline$-77,5 \%$ & $1053,8 \%$ & $322,0 \%$ & $-29,1 \%$
\end{tabular}

Evidentemente, la presencia de grupos armados ilegales ha afectado profundamente la integridad de las comunidades campesinas, negras e indígenas, donde se continúa instigando a líderes y, paralelamente, se reproduce un modelo de economía ilegal que trae consigo mafias, violencia y destrucción del tejido social (Fundación Ideas para la Paz, Consejo Internacional de Industria Sueca, y Asociación Nacio- 
nal de Empresarios en Colombia, 2011). A pesar de que la Sentencia T 1045-A, de 2010, suspendió la expedición de títulos en la zona, no ha habido garantías para la protección de los derechos de la comunidad (Vélez-Torres, 2014b, p. 55). Sus pobladores siguen siendo amenazados y obligados a desplazarse, sin que las autoridades e instituciones tomen medidas definitivas al respecto.

En este sentido, es importante resaltar la tendencia observada en cuanto al cambio de prácticas de los grupos armados ilegales. Como se observa en la Tabla 2, la variación porcentual de la tasa de homicidios entre los años 2000 y 2010 es positiva, y superior a la observada entre los años 2010 y 2013, mientras que en los desplazamientos se observa una variación contraria, es decir, disminución entre los años 2000 y 2010, y exagerado aumento entre 2010 y 2013. Estas variaciones van en línea con lo expuesto en párrafos precedentes: aunque ha sido apaciguado el desmedido avance de las titulaciones y concesiones mineras en el territorio, la presencia y llegada de grupos al margen de la ley vinculados a la minería ilegal ha dado paso a procesos de desplazamiento y de violencia que deja en claro la situación de vulnerabilidad de estas comunidades rurales.

\section{Conclusiones}

La implementación de políticas económicas de carácter neoliberal durante finales del siglo XX fue generalizada en América Latina. Sin embargo, algunos países, particularmente aquellos que dieron el giro a la izquierda, contaron con gobiernos que, mediante intervenciones redistributivas, lograron cierta compensación social frente a la implementación de un modelo neo-extractivista, impulsado por el incremento en el precio y demanda internacional de materias primas. Colombia, si bien no dio dicho giro, apostó también al modelo extractivista, especialmente desde el primer gobierno de Uribe (2002-2006), en el que no se realizaron intervenciones redistributivas sobre esta actividad, sino que, por el contrario, se estableció un andamiaje institucional para fomentar la llegada de capital privado a la gran minería.

Este andamiaje es evidenciado durante la feria de concesiones mineras en el año 2002, la cual marca el primer momento analítico aquí propuesto respecto a la política minera del país. Sin embargo, dicha apuesta extractivista entraría en tensión con la misma Constitución de 1991, en la cual fueron sentadas las bases que permitirían el surgimiento de estrategias de resistencia por parte de las comunidades étnicas afectadas por este tipo de actividades. La emergencia de estas estrategias constituye entonces el segundo momento y se manifiesta en los procesos organizativos llevados a cabo en Suárez frente a la gran minería. Pese al alcance de estas luchas 
y liderazgos territoriales, las comunidades siguen siendo amenazadas por grupos armados y bandas criminales vinculadas a la minería ilegal. Las acciones violentas de estos grupos dan paso al tercer momento analítico.

La periodización aquí propuesta (2000-2010 y 2010-2015) permitió, entonces, vincular los momentos analíticos con dinámicas internacionales y nacionales, rescatando el cambio en el contexto económico internacional y la transformación de las prácticas de violencia a nivel nacional, evidenciadas en el caso de Suárez. En este territorio, después de altas tasas de homicidio (2000-2010), siguieron altos niveles de desplazamiento, lo cual sugiere nuevas formas de acción de grupos ilegales frente a prácticas de resistencia en torno a la minería. Si bien esta relación escapa al alcance del presente artículo, es un punto que puede ocupar futuras agendas de investigación que busquen abordar tanto la minería, como actividad económica, como los procesos organizativos y la violencia criminal. Además, los tres momentos propuestos cuentan con los elementos analíticos necesarios para abordar otros casos a nivel nacional, en donde las actividades mineras ocupen un papel central en términos sociales y económicos.

\section{Referencias}

AHUMADA, O. (29 de septiembre de 2014). En el limbo jurídico, 8.840 solicitudes de títulos mineros. El Tiempo. Recuperado de http://www.eltiempo.com/archivo/documento/CMS-1461226o

ARARAT, L., MINA, E., ROJAS, A., SOLARTE, A., VANEGAS, G., VARGAS, L., Y VEGA, A. (2013). La Toma Historias de territorio, resistencia y autonomía en la cuenca del Alto Cauca. Popayán: Observatorio de Territorios Étnicos-Pontificia Universidad Javeriana, Consejo Comunitario Afrodescendiente de La Toma, Suárez, Cauca.

ARSEL, M., HOGENBOOM, B., Y PELLEGRINI, L. (2016). The extractive imperative in Latin America. The Extractive Industries and Society, 3(4), 880-887.

BEBBINGTON, A. (2012). Underground political ecologies: the second annual lecture of the Cultural and Political Ecology Speciality Group of the Association of American Geographers. Geoforum, 43, 1152-1162.

BÉRTOLA, L., Y OCAMPO, J. (2013). El desarrollo económico de América Latina desde la Independencia. México: FCE.

BOGLIACINO, F., Y ROJAS-LOZANO, D. (2017). La evolución de la desigualdad en Latinoamérica en el siglo XXI: patrones, determinantes y causas (Documento de Trabajo). Facultad de Ciencias 
Económicas y Centro de Investigaciones para el Desarrollo, Universidad Nacional de Colombia. Recuperado de https://ideas.repec.org/p/col/ooo178/o15307.html

BOLAÑOS, E. (7 de marzo de 2012). El brillo opaco de Suárez y Buenos Aires. El Espectador. Recuperado de https://www.elespectador.com/noticias/nacional/el-brillo-opaco-de-suarez-y-buenos-aires-articulo-330990

BUENAVENTURA, A., Y TRUJILLO, D. (2011). Historia doble del Cauca. Reconstrucción de las historias locales de Suárez y Buenos Aires, Cauca. Cali: Editorial Académica Española.

BURCHARDT, H., Y DIETZ, K. (2014). (Neo-) extractivism - a new challenge for development theory from Latin America. Third World Quarterly, 35(3), 468-486.

CABRERA, M., Y J. FIERRO. (2013). Implicaciones ambientales y sociales del modelo extractivista en Colombia. En L. Garay (Dir.), Minería en Colombia. Fundamentos para superar el modelo extractivista (pp. 89-124). Bogotá: Contraloría General de la República.

CENTRO DE ESTUDIOS PARA LA JUSTICIA SOCIAL «TIERRA DIGNA». (2011). Reflexiones sobre los impactos en Derechos Humanos de la minería a gran escala en Colombia y América Latina. Recuperado de http://goo.gl/mRLJvK

CENTRO DE ESTUDIOS PARA LA JUSTICIA SOCIAL «TIERRA DIGNA». (2015). Suspendidas 516 áreas estratégicas mineras que ocupan el 20.3\% del país. Recuperado de http://tierradigna. org/mineria-metales/2015/05/15/suspendidas-516-areas-estrategicas-mineras/

COLMENARES, G. (1973). Popayán: una sociedad esclavista, 1680-180o (Vol. 2). Cali: Universidad del Valle, División de Humanidades.

COLMENARES, G. (1979). Historia económica y social de Colombia (Vol. 2). Bogotá: La Carreta.

CONDE, M. (2017). Resistance to Mining. A Review. Ecological Economics, 132, 80-9o.

CONGRESO DE LA REPÚBLICA DE COLOMBIA. (8 de septiembre de 2001). Ley 685 De 2001. Diario Oficial No. 44.545.

CORNIA, G. (2012). Inequality Trends and their Determinants. Latin America over 1990-2010. UNU-WIDER, Working Paper No. 2012/09.

DEFENSORÍA DEL PUEBLO. (2015). La minería sin control. Un enfoque desde la vulneración de los Derechos Humanos. Bogotá: Defensoría del Pueblo.

DEPARTAMENTO ADMINISTRATIVO NACIONAL DE ESTADÍSTICA - DANE. (1998). Plan Nacional de Desarrollo 1998-2002. Recuperado de https://colaboracion.dnp.gov.co/cdt/pnd/ pastrana2_contexto_cambio.pdf

DEPARTAMENTO ADMINISTRATIVO NACIONAL DE ESTADÍSTICA - DANE.(2002). Plan Nacional de Desarrollo 2002-2006. Recuperado de https://colaboracion.dnp.gov.co/cdt/pnd/ pnd.pdf 
DEPARTAMENTO ADMINISTRATIVO NACIONAL DE ESTADÍSTICA - DANE.(2005). Censo General 2005.

DEPARTAMENTO ADMINISTRATIVO NACIONAL DE ESTADÍSTICA - DANE.(2014). Plan Nacional de Desarrollo 2014-2018. Recuperado de https://colaboracion.dnp.gov.co/cdt/pnd/ pnd\%202014-2018\%20tomo\%201\%2ointernet.pdf

DUARTE, C. (2012a). Gobernabilidad minera: cronologías legislativas del subsuelo en Colombia. Recuperado de https://gobernabilidadminera.files.wordpress.com/2012/o1/gobernabilidad-minera-cronologicc81as-legislativas-del-subsuelo-en-colombia.pdf

DUARTE, C. (2012b). La posesión precaria y el sistema de ocupación neogranadino. Cronologías de gobernabilidad minera colombiana. Recuperado de http://gobernabilidadminera.wordpress. com/2012/01/10/cronologia-no-1-la-posesion-precaria-y-el-sistema-de-ocupacion-neogranadino/\#comments

EL ECONOMISTA. (2010). Minería, un sector en recuperación que deja 200 muertos en América en 2010. Recuperado de http://www.eleconomista.es/medio-ambiente/noticias/2539811/10/10/ La-mineria-un-sector-en-recuperacion-que-deja-20o-muertos-en-America-en-2010.html

EL ESPECTADOR. (2011). Amenazas de muertey minería. Recuperado de http://www.elespectador. com/noticias/judicial/amenazas-de-muerte-y-mineria-ilegal-articulo-269734

ESTRADA, J. (2006). Orden neoliberal y reformas estructurales en la década de 1990. Ciencia Política, 1(1), 141-178.

FIERRO, J. (2012). Políticas mineras en Colombia. Bogotá: ILSA.

FUNDACIÓN IDEAS PARA LA PAZ, CONSEJO INTERNACIONAL DE INDUSTRIA SUECA, Y ASOCIACIÓN NACIONAL DE EMPRESARIOS EN COLOMBIA. (2011). Entornos complejos: Buenaventura. Recuperado de http://www.ideaspaz.org/publications/posts/916

GARAY, L. J. (Dir.) (2013). Minería en Colombia. Fundamentos para superar el modelo extractivista. Bogotá: Contraloría General de la República.

GARAY, L. J. (Dir.) (2014a). Minería en Colombia. Daños ecológicos y socio-económicos

Y CONSIDERACIONES SOBRE UN MODELO MINERO ALTERNATIVO. BOGOTÁ: CONTRALORÍA GENERAL DE LA REPÚBLICA.

GARAY, L. J. (Dir.) (2014b). Minería en Colombia. Control público, memoriay justicia socio-ecológica, movimientos sociales y posconflicto. Bogotá: Contraloría General de la República

GÖBEL, B., Y ULLOA, A. (2014). Extractivismo minero en Colombia y América Latina. Bogotá: Universidad Nacional de Colombia. 
GUDYNAS, E. (2009). Diez tesis urgentes sobre el nuevo extractivismo. En J. Schuldt, A. Acosta, A. Barandiarán, A. Bebbington, M. Folchi, CEDLA - Bolivia, A. Alayza, y E. Gudynas (eds.), Extractivismo, políticay sociedad (pp.187-225). Quito: Centro Andino de Acción Popular y Centro Latinoamericano de Ecología Social.

GUDYNAS, E. (2012). Estado compensador y nuevos extractivismos: Las ambivalencias del progresismo sudamericano. Nueva sociedad, 237, 128-146.

HINCAPIÉ, S., Y LÓPEZ, J. (2016). Derechos humanos y bienes comunes. Conflictos socioambientales en Colombia. Desacatos, 51, 130-141.

IDÁRRAGA, A. (2010). Minería en Colombia: locomotora para la prosperidad de pocos. Bogotá: Censat Agua Viva.

INSTITUTO DE ESTUDIOS INTERCULTURALES. (2014). Contexto minero colombianoy regional del norte del Cauca. Cali: IEI.

MINISTERIO DE MINAS Y ENERGÍA. (2011). Irregularidades encontradas en la titulación minera del país. Comunicado de prensa 032 de 2011. Bogotá.

MOLANO, A. (21 de agosto de 2010). A punto de Sangre. El Espectador. Recuperado dehttps:// www.elespectador.com/opinion/punto-de-sangre-columna-220216

MOZZO, J. (17 de agosto de 2010). Colombia echa agua fría a su «bonanza» minero-petrolera. Reuters. Recuperado de https://www.reuters.com/article/mineria-colombia-regalias idAR$\mathrm{N} 1715949320100817$ ? rpc $=444$

NEGRETE, R. (2013). Derechos, minería y conflictos. Aspectos normativos. En L. Garay (Dir.), Minería en Colombia. Fundamentos para superar el modelo extractivista (pp. 23-54). Bogotá: Contraloría General de la República.

OCAMPO, J. A. (1984). Colombia y la economía mundial 1830-1910. Bogotá: Siglo Veintiuno.

OCAMPO, J. A., JUNGUITO, R., Y OSPINA, P. N. (1995). La estrategia económica de 'El Salto Social'. Bogotá: Fundación Friedrich Ebert de Colombia.

OFFEN, K. (2003). The territorial turn: Making black territories in Pacific Colombia. Journal of Latin American Geography, 2(1), 43-73.

PANIZZA, F. (2005). Unarmed utopia revisited: the resurgence of left-of-center politics in Latin America. Political Studies, 53, 716-734.

PARDO, L. (2013). Propuestas para recuperar la gobernanza del sector minero colombiano. En L. Garay (Dir.), Minería en Colombia. Fundamentos para superar el modelo extractivista (pp. 175208). Bogotá: Contraloría General de la República.

REVISTA SEMANA. (2013). Minería ilegal: entre el oro y el crimen. Recuperado de http://www. semana.com/nacion/articulo/oro-crimen-mineria-ilegal/338107-3 
REVISTA SEMANA. (2014). «Es más rentable para los ilegales explotar oro que coca». Recuperado de https://www.semana.com/nacion/articulo/la-rentabilidad-de-la-mineria-ilegal-en-colombia/397956-3

REVISTA SEMANA. (2016). Las protuberantes fallas en entrega de títulos mineros. Recuperado de http://www.semana.com/nacion/articulo/fallas-en-entrega-de-titulos-mineros-en-colom$\mathrm{bia} / 484510$

RIVERA, L., VELANDIA, M., CONRADO, S., BENAVIDES, A., GARZÓN, M., Y YEPES, A. (2012). Minería, conflictos sociales y violación de derechos humanos en Colombia. Bogotá: CINEP/PPP.

ROJAS, C. (2009). Colombia's neoliberal regime of governance: securitization by dispossession. En L. Macdonald y A. Ruckert (eds.), Post-Neoliberalism in the Americas (pp. 231-245). Basingstoke: Palgrave Macmillan.

RUDAS, G. (2012). La locomotora minera a toda marcha, ¿pero paga lo que debe? Razón Pública. Recuperado de https://www.razonpublica.com/index.php/econom-y-sociedad-temas-29/2691la-locomotora-minera-a-toda-marcha-ipero-paga-lo-que-debe.html

SAÑUDO, M., QUIÑONES, A., COPETE, J., DÍAZ, J., VARGAS, N., Y CÁCERES, A. (2016). Extractivismo, conflictos y defensa del territorio: el caso de los habitantes rurales del corregimiento de La Toma (Cauca-Colombia). Desafíos, 28(2), 367-409.

SCHAMIS, H. (2006). A «Left Turn» in Latin America? Populism, socialism, democratic institutions. Journal of Democracy, $4(17), 20-34$.

SILVA, S. (15 de febrero de 2015). Clamor Caucano contra la minería ilegal. El Espectador. Recuperado de https://www.elespectador.com/noticias/medio-ambiente/clamor-caucano-contra-mineria-ilegal-articulo-544260

SVAMPA, M. (2012). Consenso de los commodities, giro ecoterritorial y pensamiento crítico en América Latina. Revista Osal, 13(32), 15-38.

SVAMPA, M. (2013). «Consenso de los Commodities» y lenguajes de valoración en América Latina. Nueva sociedad, 244, 30-46.

SVAMPA, M. (2015). Commodities consensus: Neoextractivism and enclosure of the commons in Latin America. South Atlantic Quarterly, 114(1), 65-82.

VAN TEIJLINGEN, K. (2016). The 'will to improve'at the mining frontier: Neo-extractivism, development and governmentality in the Ecuadorian Amazon. The Extractive Industries and Society, 3(4), 902-911.

VARGAS, F. (2013). Minería, conflicto armado y despojo de tierras: impactos, desafíos y posibles soluciones jurídicas. En L. Garay (Dir.), Minería en Colombia. Fundamentos para superar el modelo extractivista (pp. 57-87). Bogotá: Contraloría General de la República. 
VÉLEZ, M. (2011). Collective titling and the process of institution building: The new common property regime in the Colombian Pacific. Human Ecology, 39(2), 117-129.

VÉLEZ-TORRES, I. (2014a). Governmental extractivism in Colombia: Legislation, securitization and the local settings of mining control. Political Geography, 38, 68-78.

VÉLEZ-TORRES, I. (2014b). Dimensiones del extractivismo minero en Colombia. Análisis de la racionalidad de gobierno durante la última década. Análisis Político, $27(82)$ 45-57.

VÉLEZ-TORRES, I., Y RUIZ-TORRES, G. (2015). Extractivismo neoliberal minero y conflictos socio-ambientales en Perú y Colombia. Ambiente y Sostenibilidad, 5, 3-15.

VELTMEYER, H. (2012). The natural resource dynamics of postneoliberalism in Latin America: new developmentalism or extractivist imperialism? Studies in Political Economy, $90(1), 57-85$. 